\title{
Dissociation between complete hippocampal context memory formation and context fear acquisition
}

\author{
Jessica Leake, ${ }^{1,2,5}$ Raphael Zinn, ${ }^{1,3,4,5}$ Laura Corbit, $^{2}$ and Bryce Vissel ${ }^{1,3,4}$ \\ ${ }^{1}$ Neurodegenerative Disorders, Neuroscience Department, Garvan Institute of Medical Research, Sydney 2010, Australia; \\ ${ }^{2}$ School of Psychology, The University of Sydney, Sydney 2006, Australia; ${ }^{3}$ Faculty of Medicine, University of New South Wales, \\ Sydney 2052, Australia; ${ }^{4}$ School of Life Sciences, Faculty of Science, University of Technology Sydney, Sydney 2007, Australia
}

\begin{abstract}
Rodents require a minimal time period to explore a context prior to footshock to display plateau-level context fear at test. To investigate whether this rapid fear plateau reflects complete memory formation within that short time-frame, we used the immediate-early gene product Arc as an indicator of hippocampal context memory formation-related activity. We found that hippocampal Arc expression continued to increase well past the minimal time required for plateau-level fear. This raises the possibility that context fear conditioning occurs more rapidly than complete memory formation. Thus, animals may be able to condition robustly to both complete and incomplete contextual representations.
\end{abstract}

[Supplemental material is available for this article.]

Rodents returned to a context in which they previously received footshock display fear proportional to the time they spent in that context prior to shock. When given $0-5$ sec between placement in the context and shock (placement shock interval; PSI), rodents show little or no fear at test, as measured by context-evoked freezing (Fanselow 1986, 1990; Kiernan and Westbrook 1993). This is thought to occur because context encoding requires time, and inadequate time prevents formation of a contextual memory that can be associated with shock (Fanselow 1990). However, as PSI is extended, animals show a rapid fear increment that reaches plateau at 30-40 sec PSIs (Fanselow 1990; Bevins and Ayres 1995; Wiltgen et al. 2001). This rapid conditioning is thought to reflect formation of a contextual representation adequate for association with shock (Fanselow 1990). However, the nature of this representation and whether it continues to improve past the point at which robust conditioning is supported remains unclear.

One possibility is that the fear plateau reflects complete memory formation within 30-40 sec. Thus, the contextual representation does not improve when the PSI is extended further, resulting in no additional increase in conditional fear. Alternatively, consistent with findings that context memory formation and context-shock association are anatomically separable (Huff and Rudy 2004; Matus-Amat et al. 2004), the fear plateau could reflect a rapid conditioning system that is dissociable from context memory acquisition per se. On this account, animals continue to gradually improve the contextual representation as the PSI extends beyond 30-40 sec. However, they do not require a complete contextual representation to support robust conditioning. Thus, animals can condition robustly to both complete and incomplete representations depending on PSI.

One way to begin delineating between these possibilities is to investigate the extent of hippocampal immediate-early gene (IEG) expression after PSIs longer than 30-40 sec. Hippocampal IEGs such as activity regulated cytoskeleton-associated protein (Arc) are intimately linked to neural activity and both signal and are re-

\footnotetext{
${ }^{5}$ These authors contributed equally to this work. Corresponding author: bryce.vissel@UTS.edu.au

Article is online at http://www.learnmem.org/cgi/doi/10.1101/Im.044578. 116. Freely available online through the Learning \& Memory Open Access option.
}

quired for development of behaviorally relevant context memories (Guzowski et al. 1999; Vazdarjanova and Guzowski 2004; Plath et al. 2006; Messaoudi et al. 2007; Denny et al. 2014). Thus, assessing whether hippocampal IEG expression continues to increase at PSIs longer than 30-40 sec can provide the first step to determining whether animals continue to improve their contextual representation past that point.

To begin exploring this question, we first aimed to establish the relationship between PSI and conditional freezing. Groups of mice were conditioned using $0,10,30,60,180$, or $720 \mathrm{sec}$ PSIs ( $n=12$ per group). A separate control group was exposed to the fear conditioning chamber for $720 \mathrm{sec}$ but did not receive shock ( $n=8$ per group). Twenty-four hours later, all groups were returned to the context for $15 \mathrm{~min}$ without shock. See Supplemental Methods for full details of behavioral procedures.

Freezing at all PSIs was maximal during the first 3 min of test, declined between minutes 4-6, then remained at a low level for the rest of the session. However, PSI affected both overall freezing and the rate of freezing decline across the session (Fig. 1A). Confirming these observations, there was a main effect of PSI on total conditional freezing $\left(F_{(6,73)}=31.064, P<0.001\right)$. Further, linear trend analysis showed a significant freezing decrement across the 15 min of test $\left(F_{(1,73)}=324.781, P<0.001\right)$, which differed significantly across PSI $\left(F_{(6,73)}=89.387, P<0.001\right)$. Importantly, visual inspection revealed that freezing was centered around the beginning of the session and not around the timing of shock, suggesting animals conditioned to the context and not the shock timing.

To more comprehensively assess the effect of PSI on freezing, we compared the means of the first 3 min for each group, as each group showed its respective maximal freezing during this portion of the test (Fig. 1B). An overall ANOVA confirmed that freezing was affected by PSI $\left(F_{(6,73)}=41.79, P<0.001\right)$. Post hoc comparisons confirmed that freezing was greater in the $30,60,180$, and $720 \mathrm{sec}$ PSIs relative to the no-shock, 0 or $10 \mathrm{sec}$ PSIs $(P<0.001$ for all comparisons). Further, freezing levels began to plateau at the $30 \mathrm{sec}$ PSI and post hoc comparisons revealed no significant

(C) 2017 Leake et al. This article, published in Learning \& Memory, is available under a Creative Commons License (Attribution-NonCommercial 4.0 International), as described at http://creativecommons.org/licenses/by-nc/4.0/. 
A

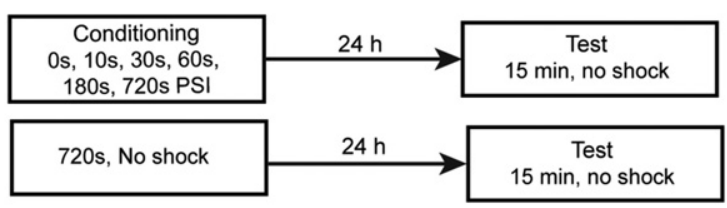

B

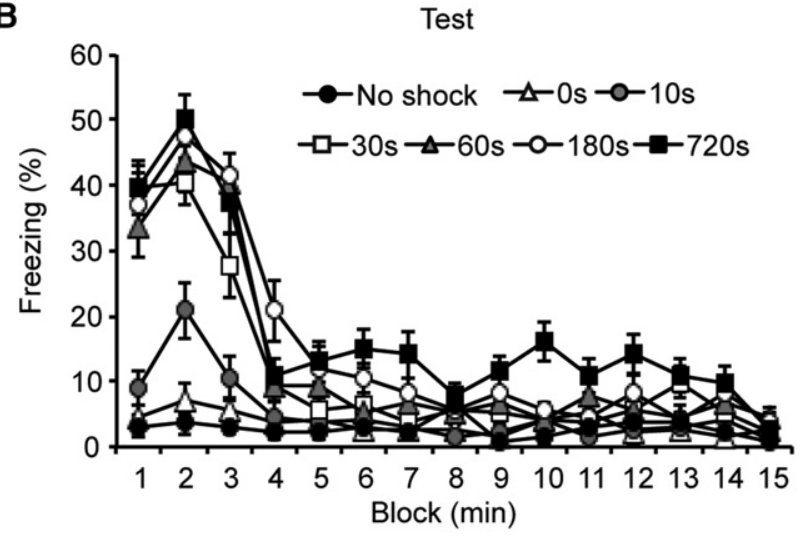

C

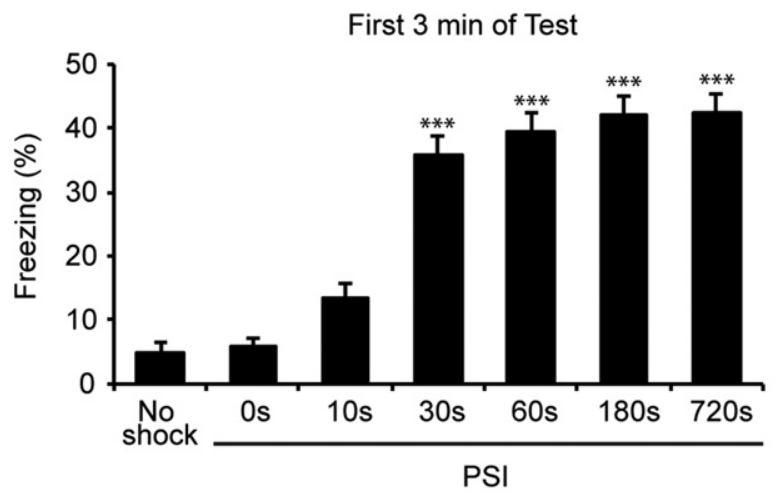

Figure 1. Conditional freezing at test is regulated by PSI. $(A)$ Experimental design. Mice were placed in a novel context for $0,30,60$, 180 , or $720 \mathrm{sec}$ prior to footshock ( $n=12$ per group). A separate group was exposed to the context for $720 \mathrm{sec}$ without shock $(n=8)$. Twenty-four hours later mice were tested for 15 min without shock. (B) Percentage freezing across the $15 \mathrm{~min}$ of test. Initial freezing levels differed across PSIs, but all groups showed maximal freezing in the first 3 min which declined over the rest of the session. Mice that received context only or shock after 0 sec showed equivalent low-level freezing. (C) Percentage freezing across the first 3 min of test. Freezing levels increased with PSI and reached a plateau by the $30 \mathrm{sec}$ PSI. Data were collected from three experiments with similar results and presented as mean $\pm \mathrm{SE}$. Significant difference from the $10 \mathrm{sec}$ PSI is indicated by (***) $P<$ 0.001 . The $30,60,180$, and $720 \mathrm{sec}$ PSIs were also each significantly different from the no shock and 0 sec PSI (not indicated).

differences between the $30,60,180$, and 720 sec PSIs $(P>0.05$ for all comparisons). Finally, freezing in 0 sec PSI and no-shock groups was low $(<5 \%)$ and did not differ significantly $(P>$ 0.05 ), indicating that exposure to the shock or the context alone was not sufficient to produce substantial freezing. These results indicate PSI mediates the level of contextual fear learning and that mice require around $30 \mathrm{sec}$ in the context prior to shock to acquire a robust fear memory.

We next asked whether the rapid freezing plateau reached after a $30 \mathrm{sec}$ PSI was associated with maximal expression of learning-related markers of plasticity. To achieve this, we conditioned animals using a 30,180, or $720 \mathrm{sec}$ PSI, which were the shortest, intermediate, and longest PSIs to produce robust freezing. We then collected the hippocampus, a region critical for formation and consolidation of context memory, either immediately or up to $360 \mathrm{~min}$ thereafter ( $n=10-12$ per group). As a control, we also collected the hippocampus from mice housed with the test animals but that did not receive context or shock exposure (naïve). After collection, the hippocampus was dissected further into CA1 and DG/CA3 hippocampal fractions, as these have distinct roles in memory formation and context encoding (Lee et al. 2004; Vazdarjanova and Guzowski 2004; Leutgeb et al. 2004). Finally, both fractions were probed for Arc protein using Western blotting (Supplemental Methods).

We first investigated the time-course of Arc expression at each PSI. To achieve this, we used an overall ANOVA on each fraction at each PSI and then performed post hoc tests comparing each time-point to naïves, which acted as the baseline. At the 30 sec PSI, the DG/CA3 fraction showed a main effect of PSI on Arc expression $\left(F_{(5,65)}=4.575, P<0.01\right.$, Fig. $\left.2 \mathrm{~B}\right)$. Arc was increased at $60 \mathrm{~min}$ post-conditioning $(P<0.01)$, and returned to baseline by 120 min post-conditioning. Interestingly, within the CA1 fraction of the same animals, there were no significant changes in Arc expression at any time point $\left(F_{(5,65)}=1.527, P>0.05\right.$, Fig. $\left.2 \mathrm{C}\right)$. Thus, Arc expression was briefly increased in DG/CA3 but not CA1 at this short PSI.

In contrast, at the $180 \mathrm{sec}$ PSI, there was a main effect of PSI in both DG/CA3 $\left(F_{(5,60)}=23.14, P<0.001\right.$, Fig. 2D) and CA1 $\left(F_{(5,60)}=7.573, P<0.001\right.$, Fig. $\left.2 \mathrm{E}\right)$. Arc was increased at $60 \mathrm{~min}$ and $120 \mathrm{~min}$ post-conditioning in both fractions $(P<0.05$ for all comparisons), and returned to baseline by $240 \mathrm{~min}$ postconditioning. Thus, this longer PSI resulted in a more sustained increase in Arc expression in both hippocampal regions.

Finally, at the $720 \mathrm{sec}$ PSI, there was a main effect of PSI in both the DG/CA3 $\left(F_{(5,64)}=31.53, P<0.001\right.$, Fig. $\left.2 \mathrm{~F}\right)$ and the CA1 $\left(F_{(5,64)}=17.50, P<0.001\right.$, Fig. $\left.2 \mathrm{G}\right)$. In the DG/CA3 fraction, Arc was increased at $60 \mathrm{~min}$ post-conditioning and remained above baseline at $120 \mathrm{~min}, 240 \mathrm{~min}$, and $360 \mathrm{~min}$ postconditioning $(P<0.05$ in all cases). In the CA1 fraction, Arc was significantly increased at $60 \mathrm{~min}$ and $120 \mathrm{~min}$ post-conditioning $(P<0.01$ in both cases), before returning to baseline by $240 \mathrm{~min}$ post-conditioning. This indicates that both the duration and regional activation of the hippocampus continues to increase well beyond the point at which mice become robustly conditioned.

Examination of the time-courses in Figure 2 suggested that PSI might also affect maximal Arc levels. To directly test this possibility, we conditioned a new cohort of animals and collected tissue $60 \mathrm{~min}$ thereafter, as $60 \mathrm{~min}$ appeared to result in maximal Arc levels at all PSIs. Arc levels were then compared directly across PSI and relative to naïves $(n=11$ per group; Fig. $3 \mathrm{~A})$.

As expected, there were main effects of PSI on Arc levels in both the CA1 $\left(F_{(3,41)}=13.15, P<0.001\right)$ and the DG/CA3 $\left(F_{(3,41)}=26.97, P<0.001\right)$. As in our previous blots, Arc was increased in the DG/CA3 fraction at all PSIs $(P<0.001$ for all comparisons; Fig. 3B,C). Further, in the CA1 fraction, the 180 and 720 sec PSIs showed significant Arc increases $(P<0.001$ for both comparisons) whereas the $30 \mathrm{sec}$ PSI did not $(P>0.05$, Fig. 3C). Most importantly, comparison across PSIs revealed a step-wise increase in Arc expression, with the $720 \mathrm{sec}$ PSI showing significantly higher Arc than the $30 \mathrm{sec}$ PSI in both fractions $(P<0.01$ for both comparisons) and the $180 \mathrm{sec}$ PSI showing an intermediate level of Arc in both fractions that was not significantly different to either the 30 or 720 sec PSIs ( $P>0.05$ for all comparisons; Fig. 3B,C). All together, these results indicate that the duration and magnitude of regional hippocampal Arc expression continues to increase well after the minimal PSI at which conditioning is robustly supported. 
A

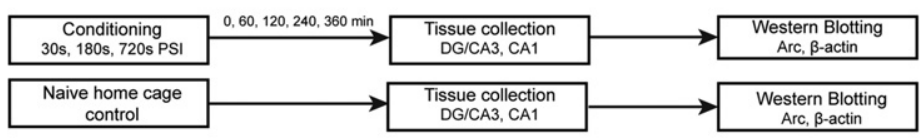

B

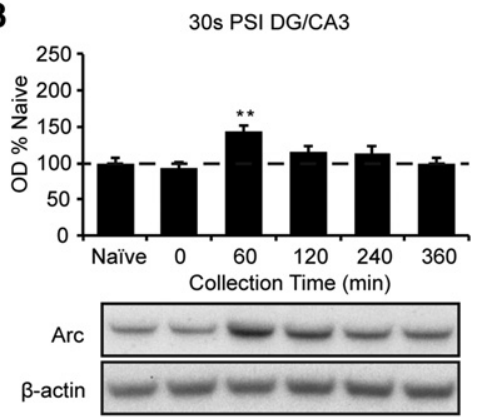

D

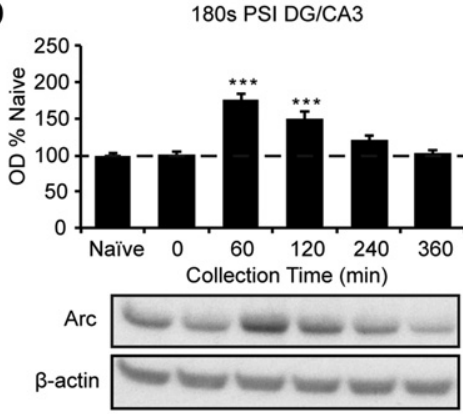

$\mathbf{F}$

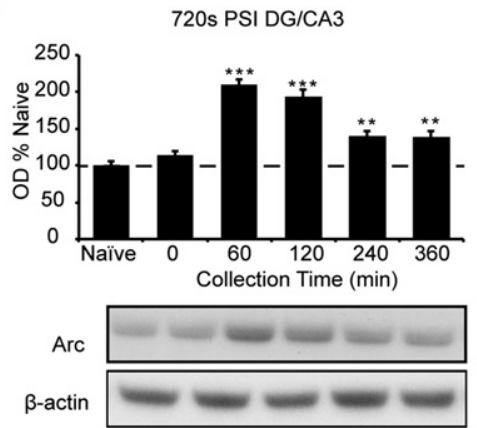

C

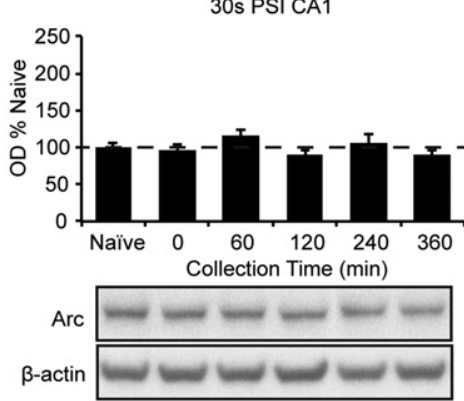

E
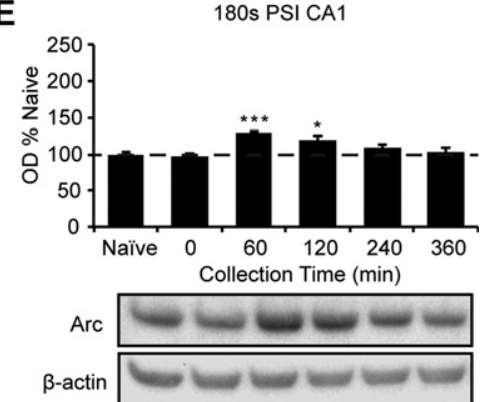

G

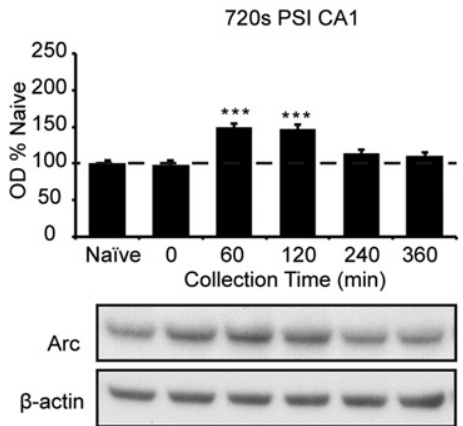

Figure 2. PSI regulates the duration of Arc expression in the hippocampal DG/CA3 and CA1 regions. (A) Experimental design. Mice ( $n=10-12$ per group) were placed in a novel context for 30,180 , or $720 \mathrm{sec}$ prior to footshock. Naïve home cage controls were included as comparators. Hippocampal DG/CA3 and CA1 fractions were collected post-conditioning and Arc and $\beta$-actin immunoreactivity were assessed. $(B-G)$ Time-courses of Arc immunoreactivity in the DG/CA3 and CA1 following conditioning at the 30,180, or $720 \mathrm{sec}$ PSI. $(B, C) 30 \mathrm{sec}$ PSI. Arc activity was increased at 60 min postconditioning in the DG/CA3 $(B)$ but not in the CA1 (C). (D,E) $180 \mathrm{sec}$ PSI. Arc activity was increased at 60 and 120 min post-conditioning in the DG $/ C A 3(D)$ and the CA1 $(E)$. $(F, G) 720 \mathrm{sec}$ PSI. Arc activity showed a notable increase at $60-360 \mathrm{~min}$ post-conditioning in the DG/CA3 $(F)$ and $60-120 \mathrm{~min}$ in the CA1 $(G)$. Images for figures $C$ and $E$ were spliced together from different sections of the same membrane for convenient viewing. Data were collected from three experiments with similar results. Data are presented as mean $+\mathrm{SE}$. Significant difference from home cage controls at each time-point is indicated by $\left(^{*}\right) P<0.05,(* *) P<0.01,\left({ }^{* *}\right) P<0.001$.

Previous work has established a relationship between hippocampal Arc and PSI by comparing long versus very short PSIs where conditioning was or was not supported, respectively (Huff et al. 2006; Lonergan et al. 2010; Nakayama et al. 2015). Confirming and expanding on this work, we found that Arc expression continues to increase even after the point at which animals establish strong conditioning. Our findings contrast with those of Pevzner et al. (2012), who found that the number of Arc mRNA-expressing hippocampal cells was similar after 30 and 300 sec context exposures, suggesting that Arc levels peak after 30 sec. This apparent contradiction could have arisen because $300 \mathrm{sec}$ was insufficient to detect the later Arc increment we found at the 720 sec PSI, or because the pattern of Arc mRNA and protein expression differs, as illustrated in other learning-related conditions (Kelly and Deadwyler 2003; McIntyre et al. 2005). Alternatively, given that individual cells can up-regulate protein expression to different levels, the number of Arc expressing cells could have reached asymptote within $30 \mathrm{sec}$ while still permitting Arc protein increases as PSI was extended. Thus, taken together, our findings and those of Pevzner et al. (2012) may be complementary rather than contradictory and could be informative of Arc biology in the setting of context learning.

What might the continuing Arc increase across PSI signify? Although Arc is required for long-term synaptic plasticity (Plath et al. 2006; Messaoudi et al. 2007), its expression is not always related to the level of learning (Kelly and Deadwyler 2003; Guzowski et al. 2006). Further, Arc has been linked to memory processes other than initial learning, including retrieval (Figge et al. 2013) and reconsolidation (Maddox and Schafe 2011). Thus, the function of Arc is likely to be complex and broad-reaching. Nonetheless, in the setting of context fear conditioning, up-regulation of Arc expression both correlates with and is required for formation of behaviorally detectable contextual fear memory (Guzowski et al. 1999; Czerniawski et al. 2011; Nakayama et al. 2015). Thus, Arc is likely to play an important role in aspects of context memory required for long-term expression such as stabilization, consolidation, or retrievability. By extension, the Arc increase we detected across the longer PSIs could reflect continuing improvement in these aspects of memory well into the session.

Alternatively, the continuing Arc increase could reflect further encoding of some aspect of the experience across the session. In our hands, animals showed maximal fear at the beginning of the session rather than around the timing of shock, so the Arc increase is unlikely to have occurred due to encoding of the different timings of shock. Further, it is unclear why Arc should continually increase if it simply encoded the duration of the session. Rather, given that context encoding depends on the hippocampus and relies on time-dependent processes such as environmental exploration and configural unification (Fanselow 2000), it is possible that the Arc increase reflects continuing encoding of the context itself. 
A
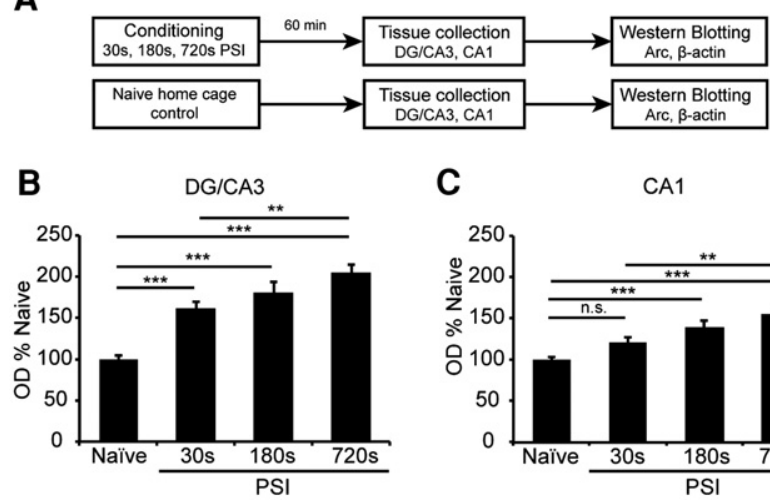

C
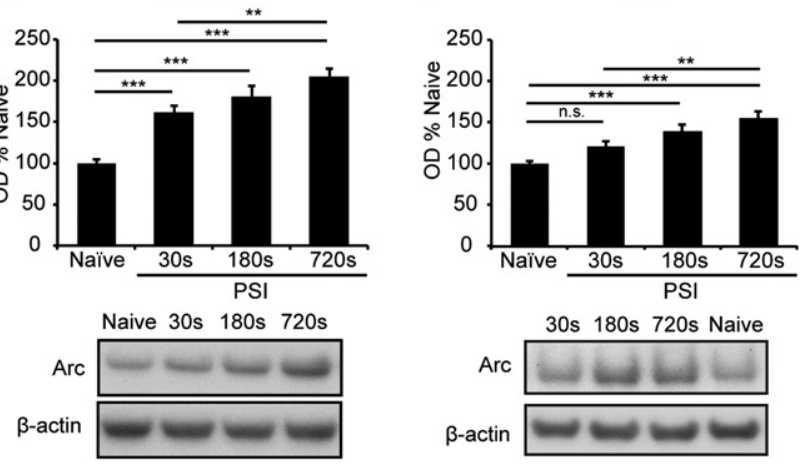

Figure 3. PSI regulates the level of Arc expression in the hippocampal DG/CA3 and CA1 regions. (A) Experiment design. Mice $(n=11$ per group) were placed in a novel context for 30,180 , or 720 sec prior to footshock. Naiive home cage controls were included as comparators. Hippocampal DG/CA3 and CA1 fractions were collected 60 min postconditioning and probed for Arc and $\beta$-actin immunoreactivity. Arc levels increased as a function of PSI in the DG/CA3 $(B)$ and the CA1 (C) regions. Data were collected from three experiments with similar results. Data are presented as mean $+\mathrm{SE}$. Significance is indicated by $\left({ }^{*}\right) P<0.05,\left({ }^{* *}\right) P<0.01,\left({ }^{* *}\right) P<0.001$. No statistical difference is indicated by n.s.

If the continuing Arc increase does indeed reflect improvement in some aspect of context memory across the session, it follows that memories formed after long PSIs are more complete than those formed after short PSIs. If this is true, then the ability of animals to condition following both short and long PSIs may mean that representation completeness is not required for successful conditioning. This feature could be adaptively important, allowing animals to condition more rapidly and across a wider range of session durations and learning circumstances.

The pattern of hippocampal activation observed in this study broadly agrees with this conclusion and with models of hippocampal context learning. The DG and CA3 are thought to play a crucial role in rapid acquisition of context memory, with the DG imposing a distinct firing pattern on the CA3 and the latter forming an auto-associative network through the extensive collaterals present in that region (Marr 1971; O'Reilly and Rudy 2001; Krasne et al. 2015). The CA1, on the other hand, is not completely understood, but is thought to play a role in a variety of both essential and modulatory functions including memory consolidation (Remondes and Schuman 2004), generalization (Basu et al. 2016), comparison (Chen et al. 2011; Duncan et al. 2012), and encoding of specific items and their inter-relation within the context (Lee et al. 2005; Griffin et al. 2007; Greene et al. 2013). Our findings that the DG/CA3 is more rapidly engaged than the CA1 therefore agree with previous work (Miyashita et al. 2009, Pevzner et al. 2012) and are consistent with the idea that the DG and CA3 lay down the initial memory framework that supports rapid conditioning (McHugh et al. 2007, McHugh and Tonegawa 2009) and that all regions subsequently expand upon this framework to create a more comprehensive representation as the session continues. Further, our findings are consistent with the idea of the DG as a regulatory gate that supports downstream activation of the CA1 and CA3 only after repeated stimulation (Hsu 2007).
Overall, our findings provide reason to believe that context fear conditioning occurs more rapidly than complete acquisition of all aspects of context memory. Thus, the level of conditioning in a given situation need not reflect the level of memory completeness, and this should be borne in mind in studies of context fear memory. Further, the idea that incomplete representations can be robustly conditioned may be informative for disorders of memory. Short PSIs that putatively produce incomplete but conditionable memories result in fear generalization to similar contexts (Westbrook et al. 1994). Since memory-related disorders such as panic disorder (Lissek et al. 2010), post-traumatic stress disorder (Lissek and van Meurs 2015), and generalized anxiety disorder (Lissek et al. 2014) often involve similar generalization, it is possible their underlying mechanism includes incomplete initial memory formation. Future studies can investigate these possibilities and further explore the consequences of incomplete memory acquisition for both emotion and behavior.

\section{Acknowledgments}

We thank Darren Saunders for extensive technical assistance with Western blotting. This work was supported by Stanley and John Roth through the Roth Foundation, the ISG Foundation in memory of Kylie, FiveX in memory of Marko Berger, David King and Doug Battersby and families, Walter and Edith Sheldon, Tony and Vivian Howland-Rose, Patricia A. Quick Foundation. The funders had no role in study design, data collection and analysis, decision to publish, or preparation of the manuscript.

Author contributions: J.L. and R.Z. contributed to conception and design, collection and assembly of data, analysis and interpretation of data, and writing and approval of final manuscript. L.C. contributed to interpretation of data, writing, and final approval of manuscript. B.V. contributed to conception and design, financial support, interpretation of data, writing, and final approval of manuscript.

\section{References}

Basu J, Zaremba JD, Cheung SK, Hitti FL, Zemelman BV, Losonczy A, Siegelbaum SA. 2016. Gating of hippocampal activity, plasticity, and memory by entorhinal cortex long-range inhibition. Science 351: aaa5694.

Bevins RA, Ayres JJB. 1995. One-trial context fear conditioning as a function of the interstimulus-interval. Anim Learn Behav 23: 400-410.

Chen J, Olsen RK, Preston AR, Glover GH, Wagner AD. 2011. Associative retrieval processes in the human medial temporal lobe: hippocampal retrieval success and CA1 mismatch detection. Learn Mem 18: 523-528.

Czerniawski J, Ree F, Chia C, Ramamoorthi K, Kumata Y, Otto TA. 2011. The importance of having Arc: expression of the immediate-early gene Arc is required for hippocampus-dependent fear conditioning and blocked by NMDA receptor antagonism. J Neurosci 31: 11200-11207.

Denny CA, Kheirbek MA, Alba EL, Tanaka KF, Brachman RA, Laughman KB, Tomm NK, Turi GF, Losonczy A, Hen R. 2014. Hippocampal memory traces are differentially modulated by experience, time, and adult neurogenesis. Neuron 83: 189-201.

Duncan K, Ketz N, Inati SJ, Davachi L. 2012. Evidence for area CA1 as a match/mismatch detector: a high resolution fMRI study of the human hippocampus. Hippocampus 22: 389-398.

Fanselow MS. 1986. Associative vs topographical accounts of the immediate shock freezing deficit in rats-implications for the response selection-rules governing species-specific defensive reactions. Learn Motiv 17: 16-39.

Fanselow MS. 1990. Factors governing one-trial contextual conditioning. Anim Learn Behav 18: 264-270.

Fanselow MS. 2000. Contextual fear, gestalt memories, and the hippocampus. Behav Brain Res 110: 73-81.

Figge DA, Rahman I, Dougherty PJ, Rademacher DJ. 2013. Retrieval of contextual memories increases activity-regulated cytoskeletonassociated protein in the amygdala and hippocampus. Brain Struct Funct 218: $1177-1196$.

Greene P, Howard M, Bhattacharyya R, Fellous J-M. 2013. Hippocampal anatomy supports the use of context in object recognition: a computational model. Comput Intell Neurosci 2013: 294878. 
Griffin AL, Eichenbaum H, Hasselmo ME. 2007. Spatial representations of hippocampal CA1 neurons are modulated by behavioral context in a hippocampus-dependent memory task. J Neurosci 27: 2416-2423.

Guzowski JF, McNaughton BL, Barnes CA, Worley PF. 1999. Environment-specific expression of the immediate-early gene Arc in hippocampal neuronal ensembles. Nat Neurosci 2: 1120-1124.

Guzowski JF, Miyashita T, Chawla MK, Sanderson J, Maes LI, Houston FP, Lipa P, McNaughton BL, Worley PF, Barnes CA. 2006. Recent behavioral history modifies coupling between cell activity and Arc gene transcription in hippocampal CA1 neurons. Proc Natl Acad Sci 103: 1077-1082.

Hsu D. 2007. The dentate gyrus as a filter or gate: a look back and a look ahead. Prog Brain Res 163: 601-613.

Huff NC, Rudy JW. 2004. The amygdala modulates hippocampus-dependent context memory formation and stores cue-shock associations. Behav Neurosci 118: 53.

Huff NC, Frank MK, Wright-Hardesty D, Sprunger P, Matus-Amat, Higgins E, Rudy JW. 2006. Amygdala regulation of immediate-early gene expression in the hippocampus induced by contextual fear conditioning. J Neurosci 26: 1616-1623.

Kelly MP, Deadwyler SA. 2003. Experience-dependent regulation of the immediate-early gene arc differs across brain regions. J Neurosci 23: 6443-6451.

Kiernan MJ, Westbrook RF. 1993. Effects of exposure to a to-be-shocked environment upon the rats freezing response-evidence for facilitation, latent inhibition, and perceptual-learning. QJExp Psychol B 46: $271-288$

Krasne FB, Cushman JD, Fanselow MS. 2015. A Bayesian context fear learning algorithm/automaton. Front Behav Neurosci 9: 112

Lee I, Yoganarasimha D, Rao G, Knierim JJ. 2004. Comparison of population coherence of place cells in hippocampal subfields CA1 and CA3. Nature 430: 456-459.

Lee I, Hunsaker MR, Kesner RP. 2005. The role of hippocampal subregions in detecting spatial novelty. Behav Neurosci 119: 145.

Leutgeb S, Leutgeb JK, Treves A, Moser MB, Moser EI. 2004. Distinct ensemble codes in hippocampal areas CA3 and CA1. Science 305: $1295-1298$

Lissek S, van Meurs B. 2015. Learning models of PTSD: theoretical accounts and psychobiological evidence. Int J Psychophysiol 98: 594-605.

Lissek S, Rabin S, Heller RE, Lukenbaugh D, Geraci M, Pine DS, Grillon C. 2010. Overgeneralization of conditioned fear as a pathogenic marker of panic disorder. Am J Psychiatry 167: 47-55.

Lissek S, Kaczkurkin AN, Rabin S, Geraci M, Pine DS, Grillon C. 2014 Generalized anxiety disorder is associated with overgeneralization of classically conditioned fear. Biol Psychiatry 75: 909-915.

Lonergan ME, Gafford GM, Jarome TJ, Helmstetter FJ. 2010. Timedependent expression of Arc and zif268 after acquisition of fear conditioning. Neural Plast 2010: 139891.

Maddox SA, Schafe GE. 2011. The activity-regulated cytoskeletal-associated protein (Arc/Arg3.1) is required for reconsolidation of a Pavlovian fear memory. J Neurosci 31: 7073-7082.

Marr D. 1971. Simple memory: a theory for archicortex. Philos Trans $R$ Soc Lond B Biol Sci 262: 23-81.
Matus-Amat P, Higgins EA, Barrientos RM, Rudy JW. 2004. The role of the dorsal hippocampus in the acquisition and retrieval of context memory representations. J Neurosci 24: 2431-2439.

McHugh TJ, Tonegawa S. 2009. CA3 NMDA receptors are required for the rapid formation of a salient contextual representation. Hippocampus 19: $1153-1158$.

McHugh TJ, Jones MW, Quinn JJ, Balthasar N, Coppari R, Elmquist JK, Lowell BB, Fanselow MS, Wilson MA, Tonegawa S. 2007. Dentate gyrus NMDA receptors mediate rapid pattern separation in the hippocampal network. Science 317: 94-99.

McIntyre CK, Miyashita T, Setlow B, Marjon KD, Steward O, Guzowski JF, McGaugh JL. 2005. Memory-influencing intra-basolateral amygdala drug infusions modulate expression of Arc protein in the hippocampus. Proc Natl Acad Sci 102: 10718-10723.

Messaoudi E, Kanhema T, Soulé J, Tiron A, Dagyte G, da Silva B, Bramham CR. 2007. Sustained Arc/Arg3.1 synthesis controls long-term potentiation consolidation through regulation of local actin polymerization in the dentate gyrus in vivo. J Neurosci 27: $10445-10455$.

Miyashita T, Kubik S, Haghighi N, Steward O, Guzowski JF. 2009. Rapid activation of plasticity-associated gene transcription in hippocampal neurons provides a mechanism for encoding of one-trial experience. J Neurosci 29: 898-906.

Nakayama D, Iwata H, Teshirogi C, Ikegaya Y, Matsuki N, Nomura H. 2015. Long-delayed expression of the immediate early gene Arc/Arg3. 1 refines neuronal circuits to perpetuate fear memory. J Neurosci 35: 819-830.

O'Reilly RC, Rudy JW. 2001. Conjunctive representations in learning and memory: principles of cortical and hippocampal function. Psychol Rev 108: 311 .

Pevzner A, Miyashita T, Schiffman AJ, Guzowski JF. 2012. Temporal dynamics of Arc gene induction in hippocampus: relationship to context memory formation. Neurobiol Learn Mem 97: 313-320.

Plath N, Ohana O, Dammermann B, Errington ML, Schmitz D, Gross C, Mao XS, Engelsberg A, Mahlke C, Welzl H, et al. 2006. Arc/Arg3.1 is essential for the consolidation of synaptic plasticity and memories. Neuron 52: 437-444.

Remondes M, Schuman EM. 2004. Role for a cortical input to hippocampal area CA1 in the consolidation of a long-term memory. Nature 431: 699-703.

Vazdarjanova A, Guzowski JF. 2004. Differences in hippocampal neuronal population responses to modifications of an environmental context: evidence for distinct, yet complementary, functions of CA3 and CA1 ensembles. J Neurosci 24: 6489-6496.

Westbrook R, Good A, Kiernan M. 1994. Effects of the interval between exposure to a novel environment and the occurrence of shock on the freezing responses of rats. Q J Exp Psychol 47: 427-446.

Wiltgen BJ, Sanders MJ, Behne NS, Fanselow MS. 2001. Sex differences, context preexposure, and the immediate shock deficit in Pavlovian context conditioning with mice. Behav Neurosci 115: 26-32.

Received November 9, 2016; accepted in revised form January 20, 2017. 


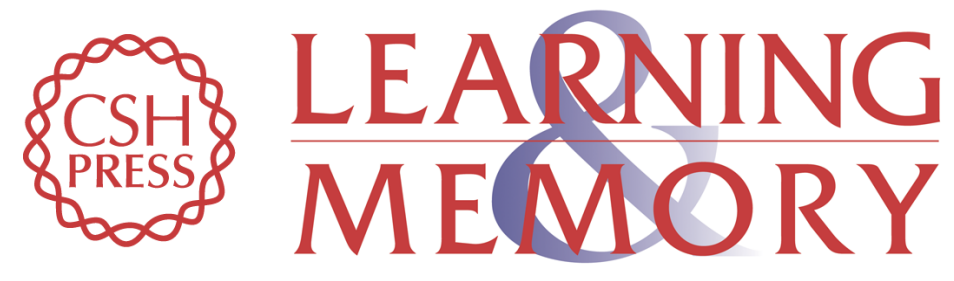

\section{Dissociation between complete hippocampal context memory formation and context fear acquisition}

Jessica Leake, Raphael Zinn, Laura Corbit, et al.

Learn. Mem. 2017, 24:

Access the most recent version at doi:10.1101/lm.044578.116

\section{Supplemental http://learnmem.cshlp.org/content/suppl/2017/03/10/24.4.153.DC1 Material}

References This article cites 43 articles, 16 of which can be accessed free at: http://learnmem.cshlp.org/content/24/4/153.full.html\#ref-list-1

Creative This article, published in Learning \& Memory, is available under a Creative Commons Commons License (Attribution-NonCommercial 4.0 International), as described at License http://creativecommons.org/licenses/by-nc/4.0/.

Email Alerting Receive free email alerts when new articles cite this article - sign up in the box at the Service top right corner of the article or click here. 